\title{
Profusão terminológica na denominação das práticas pedagógicas da Educação Básica durante a pandemia de COVID-19
}

\author{
Daniela Erani Monteiro Will ${ }^{1}$ \\ Roseli Zen Cerny ${ }^{2}$ \\ Marina Bazzo de Espíndola ${ }^{3}$ \\ Josimar Lottermann ${ }^{4}$
}

\section{RESUMO}

Este artigo analisa um dos aspectos do contexto educacional vivenciado durante o distanciamento social causado pela pandemia de Covid-19: a profusão de termos gerados para denominar as ações empreendidas para dar continuidade ao ano letivo na Educação Básica. O objetivo é compreender essas terminologias e refletir sobre as implicações dessas caracterizações para o campo da tecnologia educacional a partir da perspectiva crítica. Foi realizado um estudo documental, de caráter exploratório, abarcando legislações estaduais e os documentos oficiais das Secretarias Estaduais de Educação brasileiras. Os resultados apontam uma diversidade de termos novos sem definições conceituais ou legais e uma ausência quase total da terminologia "Educação a Distância".

Palavras-chave: Terminologias. Pandemia. Ensino Remoto. Ensino não presencial. Educação Básica.

\footnotetext{
1.danielamwill@gmail.com - Universidade Federal de Santa Catarina

2 roseli.cerny@ufsc.br - Universidade Federal de Santa Catarina

${ }^{3}$ marina.bazzo.espindola@ufsc.br - Universidade Federal de Santa Catarina

${ }^{4}$ josimarlottermann@gmail.com - Rede Municipal de Ensino de Florianópolis
} 


\section{Terminological profusion in the denomination of basic education pedagogical practices during the COVID-19 pandemic}

\section{ABSTRACT}

This article analyzes one of the aspects of the educational context experienced during the social isolation caused by the Covid-19 pandemic: the profusion of terms born to denominate the actions undertaken to allow the school year to continue in Basic Education. The aim is to comprehend these terminologies and to reflect about its implications to the field of educational technology, from the critical perspective. We have made an exploratory documental analysis of Brazilian's states legislation and the official documents published by the States' Education Departaments. The results point to a diversity of new terms without conceptual or legal definitions and an almost full absence of the terminology "Distance Education".

Keywords: Terminologies. Pandemic. Remote Teaching. Remote Education. Basic Education. 
O presente artigo se propõe a analisar um dos aspectos do contexto educacional vivenciado durante o distanciamento social causado pela pandemia de COVID-19: a profusão de termos gerados para denominar as ações empreendidas para dar continuidade ao ano letivo na Educação Básica.

A pandemia mundial ocasionada pela doença COVID-19, transmitida pelo novo coronavírus (SARS-CoV-2), implicou mudanças estruturais em todos os setores devido à necessidade de distanciamento social. No Brasil, como ocorreu em quase todo o mundo, as instituições educativas, públicas e privadas, viram-se desafiadas a implementar ações pedagógicas para a manutenção da relação de ensino e aprendizagem entre professores e estudantes, sem atividades presenciais.

A realização dessas ações está amparada no Art. 32 da Lei de Diretrizes e Bases da Educação Nacional (LDB) 9394/96, parágrafo 4º o qual indica que: "O Ensino Fundamental será presencial, sendo o Ensino a Distância utilizado como complementação da aprendizagem ou em situações emergenciais (BRASIL, 1996)". No caso do Ensino Médio, a oferta por meio da Educação a Distância (EaD) é destinada "aos jovens e adultos insuficientemente escolarizados", como citado no Art. 87, $\S 3^{\circ}$ (BRASIL, 1996). Ainda, recentemente, foi possibilitada pela Res. CNE/CEB n 3/2018 a oferta de até $30 \%$ de atividades a distância (BRASIL, 2020).

No dia $1^{\circ}$ de abril de 2020, a presidência da república editou a Medida Provisória n 934, que "estabelece normas excepcionais sobre o ano letivo da Educação Básica e do Ensino Superior, decorrentes das medidas para enfrentamento da situação de emergência de saúde pública" (BRASIL, 2020a). O Art. $1^{\circ}$ indica que as instituições de Educação Básica ficam dispensadas, em caráter excepcional, da obrigatoriedade de observância ao mínimo de dias de efetivo trabalho escolar, desde que cumprida a carga horária mínima anual estabelecida nos referidos dispositivos, observadas as normas a serem editadas pelos respectivos sistemas de ensino (BRASIL, 2020).

Nos Estados e municípios brasileiros, as atividades escolares foram inicialmente suspensas, mas com a iminência da ampliação do período de quarentena, coube às redes e instituições de ensino a proposição de práticas pedagógicas que pudessem atender ao contexto de distanciamento social. De acordo com um levantamento realizado pela União Nacional dos Dirigentes Municipais de Educação (UNDIME, 2020), em agosto de 2020, um total de 96\% das escolas municipais brasileiras realizavam atividades pedagógicas não presenciais na pandemia.

O Parecer CNE/CP n 05/2020 de 30 de abril de 2020, por exemplo, cita "atividades não presenciais", "atividades pedagógicas não presenciais", "atividades pedagógicas remotas" e "atividades remotas", para se referir às práticas escolares realizadas na pandemia (BRASIL, 2020b). Os Estados, por sua vez, publicaram normas específicas para atender à situação pandêmica e criaram estratégias e programas visando à manutenção do serviço escolar nesse período, segundo suas concepções e intencionalidades.

Apesar de a LDB citar a Educação a Distância como possibilidade ao ensino presencial em casos emergenciais, inicialmente, percebeu-se, tanto por parte dos profissionais da área quanto 
nos primeiros textos oficiais federais, que as práticas pedagógicas realizadas durante a pandemia não estavam sendo denominadas de tal forma. Pelo contrário, foi possível observar uma profusão de termos para caracterizar as novas formas de realização do processo de ensino e aprendizagem.

Esse cenário trouxe indagações: como as práticas pedagógicas foram denominadas nas legislações e demais documentos oficiais dos diferentes Estados brasileiros? Há uma unidade ou convergência terminológica para se referir a essas práticas? As tecnologias de informação e comunicação, essenciais à realização das ações pedagógicas na pandemia, têm sido utilizadas nessas nomeações? Que reflexões essas escolhas suscitam para o campo da tecnologia educacional?

Mill (2018), na apresentação da obra Dicionário Crítico de Educação e Tecnologias e de Educação a Distância, afirma que as áreas de conhecimento Educação e Tecnologias e Educação a Distância são embrionárias e lacunares, caracterizando-se como campo fértil para uma profusão terminológica que envolve um vasto conjunto de conceitos. Tal fato tem dificultado as atividades e as ações de quem pensa e faz educação pela integração de tecnologias.

Concordando com Mill (2018), entende-se que a profusão terminológica, por vezes incorreta e incoerente, pode promover equívocos elementares em pesquisas e políticas públicas voltadas para a incorporação das Tecnologias Digitais de Informação e Comunicação (TDIC) no âmbito educacional.

Assim, uma possível profusão de termos merece uma identificação, reflexão e análise mais minuciosa, pois a linguagem é um elemento integrante da vida cotidiana, tendo fortes influências políticas e ideológicas. Como coloca Wenger (2013, p. 252), "um vocabulário adequado é importante porque os conceitos que usamos para compreender o mundo direcionam a nossa percepção e as nossas ações".

Buscando compreender essa complexa realidade, que envolve linguagem, tecnologias e educação, este artigo traz uma síntese das denominações das práticas pedagógicas utilizadas nas legislações e demais documentos oficiais estaduais ${ }^{5}$ e distrital publicados durante a pandemia da COVID-19, com o intuito de refletir sobre as implicações dessas nomenclaturas para o campo da tecnologia educacional. Para isso, foi realizado um estudo documental, de caráter exploratório, que abarcou as legislações estaduais brasileiras, bem como as orientações oficiais desenvolvidas pelas Secretarias Estaduais de Educação (SEE) no período de março a outubro de 2020. As consultas foram realizadas por meio da verificação dos documentos disponibilizados nos sites das SEEs e dos Conselhos Estaduais de Educação (CEE).

\section{TERMINOLOGIAS E TECNOLOGIA NA DENOMINAÇÃO DAS PRÁtICAS DA EDUCAÇÃO BÁSICA NA PANDEMIA}

As práticas pedagógicas desenvolvidas durante a pandemia têm se efetivado por meio de tecnologias, sejam elas antigas ou emergentes, analógicas ou digitais, físicas ou virtuais. No entanto, o uso dessas tecnologias não tem sido foco de debate e da formação dos professores,

\footnotetext{
${ }^{5}$ A partir desse momento do texto, quando há referência às secretarias estaduais de educação e/ou aos estados, o Distrito Federal também estará incluído.
} 
naturalizando um uso acrítico, reproduzindo as práticas cotidianas vivenciadas na escola. Para Selwyn (2011, p. 1), "o uso da tecnologia em contextos educacionais parece ter se tornado tão corriqueiro, que, para muitos, entrou no universo do 'senso comum'”. A preocupação recai sobre o uso instrumental - ferramentas e aplicativos - em detrimento da visão de que "como quaisquer outras tecnologias, a tecnologia educacional está intrinsecamente associada a aspectos sociais, culturais, econômicos e políticos da sociedade" (SELWYN, 2011, p. 38). Essa invisibilidade das tecnologias abre caminho para a entrada das corporações e a consequente mercantilização da educação.

Analisar os documentos oficiais que orientam a educação é, portanto, algo que exige olhar e compreender as influências que estão presentes na construção dos textos políticos. Diversos organismos internacionais como a ONU, UNESCO, OCDE e Banco Mundial têm dedicado esforços para a criação de políticas ditas universais. Essas políticas são alinhadas a visões de mundo construídas a partir de países centrais e de grandes conglomerados empresariais que buscam não apenas manter as lógicas do capital, mas ampliá-las. Pesquisadores e estudiosos das políticas educacionais (IWASSO, 2010; FOSTER, 2013; FREITAS, 2014; SHIROMA et al., 2017) têm apontado, há alguns anos, que a integração das tecnologias ao currículo escolar, a partir de um modelo mercadológico, também tem contribuído para formação humana sob a ótica e interesses do capital.

Faz-se importante destacar que se partiu do pressuposto, tal como defende Feenberg (2018), de que as tecnologias não são neutras relativamente aos valores, no entanto também não são determinantes; são desenvolvidas a partir de contingências históricas e não apenas pelo seu valor técnico, mas, de igual modo, político.

As bases da teoria crítica da tecnologia proposta pelo autor supracitado possibilitam um olhar privilegiado sobre a integração das tecnologias contemporâneas aos processos educacionais, não as reduzindo exclusivamente à instrumentalidade técnica, mas propondo a democratização de todos os processos que envolvem a produção e o uso das tecnologias, compreendendo-as enquanto fenômeno técnico, social, histórico e político. Para Habowski (2020, p. 82)

Tais discussões na educação provocam o reconhecimento das dimensões interdependentes entre técnica, ciência, linguagem, poder, cognição, ideologia e vida social, cujas apropriações exigem debate político e esforço para transformar a tecnologia em potencial emancipador da experiência, para além das ambições técnicas de fim em si.

Nesse sentido, torna-se fundamental que as instituições públicas - e aqui destaca-se a escola - assumam o protagonismo de formar as próximas gerações com uma visão crítica sobre as tecnologias, problematizando todos os aspectos e, em especial, que sejam "vistas como objetos profundamente 'culturais' - parte de um corpo de conhecimento compartilhado entre pessoas e passado de geração a geração" (SELWYN, 2011, p. 17).

No campo da integração curricular das tecnologias, não importa apenas pesquisar sobre os usos destas na educação ou seus aspectos instrumentais, e sim, especialmente, tal como defende Selwyn, evidenciar que o foco não deve estar nos "artefatos técnicos, ferramentas e aplicativos em si, mas, sim, nas práticas e atividades que os rodeiam, nos significados que as 
pessoas thes atribuem e nas relações sociais e estruturas às quais as tecnologias se ligam". (SELWYN, 2011, p. 3).

Para Selwyn (2016), a linguagem também é uma dessas práticas, sendo altamente política tanto na sua natureza como no seu efeito. A linguagem utilizada no campo da tecnologia educacional não deve ser tratada simplesmente como palavras, termos, frases e declarações benignas ou neutras. Pelo contrário, é um meio poderoso de fazer avançar os interesses e agendas de alguns grupos sociais sobre os interesses de outros. Dessa forma, a base linguística limitada é um problema sério para qualquer pessoa preocupada com o potencial democrático da tecnologia digital na educação.

Selwyn (2016, n. p., tradução livre) complementa ao afirmar que:

as formas restritas de linguagem que prevalecem em qualquer área da sociedade desempenham um papel fundamental na manutenção dos parâmetros do que é, e do que não é visto como preferível e possível. A linguagem, portanto, precisa ser reconhecida como um elemento chave para informar ideias e ações de formação dentro de qualquer contexto educacional. Embora possa parecer uma preocupação relativamente trivial, deve ser dada muita atenção à linguagem usada para retratar o uso da tecnologia digital na educação.

O autor lembra, ainda, que muito pouco do discurso na área de educação e tecnologias poderia ser descrito como objetivo, preciso ou com nuances apropriadas. Em vez disso, a linguagem utilizada na educação para descrever processos e práticas digitais tende a ser carregada de valor (SELWYN, 2016).

Oliveira (2011, p. 30), ancorada nos conceitos de Bakhtin, considera que a linguagem "adquire importância primordial nas relações professor/aluno/escola/relações sociais, pois a educação como prática social é uma atividade ligada às relações entre as classes e se constitui como forma concreta dessas relações". Sendo assim, as palavras são carregadas de sentidos e expressam diferentes perspectivas.

Dessa forma, pode-se perceber que as expressões que utilizamos são importantes, pois indicam posicionamentos, valores, visões de mundo e, no caso da educação, apontam, ainda, perspectivas relativas às práticas pedagógicas tanto em seus aspectos políticos quanto didáticos, interferindo no desenvolvimento dessas práticas.

\subsection{Metodologia}

Realizou-se um estudo documental, de caráter exploratório, que abarcou as legislações estaduais, bem como os demais documentos oficiais desenvolvidos pelas Secretarias Estaduais de Educação do Brasil.

Caracteriza-se como um estudo exploratório, pois foi realizado um levantamento abrangente acerca de um tema recente, com o objetivo de oferecer uma síntese das terminologias usadas pelos Estados brasileiros para designar as práticas pedagógicas desenvolvidas na pandemia.

Foram considerados como fontes de informação tanto os documentos legais - portarias, pareceres, resoluções - quanto as informações orientadoras publicadas nos sites das secretarias, 
identificadas como orientações oficiais. Os documentos apresentam-se de forma textual; já as informações possuem a forma de guias, manuais, avisos, notícias, tutoriais - textuais e audiovisuais.

As consultas foram realizadas nos 27 sites das SEEs e em 12 sites de Conselhos Estaduais de Educação, no período de março a outubro de 2020.

No campo da educação, já se reconhece que quantidade e qualidade são propriedades interdependentes de um fenômeno (GHEDIN; FRANCO, 2008). Nesse sentido, foram realizadas descrições quantitativas de forma a consubstanciar as análises qualitativas do objetivo de estudo. Assim, foi produzido um mapeamento numérico das terminologias utilizadas nos Estados, bem como tecidas reflexões relacionadas entre tecnologia e educação.

\subsection{Terminologias utilizadas nas legislações Estaduais e nas orientações oficiais das Secretarias Estaduais de Educação}

A procura inicial deu-se pelos dados nos sites das secretarias de cada Estado e do Distrito Federal, quando foi identificado que boa parte das redes possuíam informações organizadas em seus sites, incluindo aquelas sobre as atividades pedagógicas durante a pandemia. Algumas redes, porém, não possuíam nitidamente as informações quanto às propostas para a continuidade da educação escolar frente ao distanciamento social forjado na pandemia. Em alguns casos, foi encontrada alguma informação apenas no item Notícias. Não havia, ao menos, uma página no site destinada às orientações sobre as atividades escolares durante a pandemia, mas apenas informações "soltas". As desigualdades das redes de ensino brasileiras revelam-se, inclusive, na estrutura e na forma de apresentação das informações nos sites.

Quanto às fontes legais, iniciou-se a busca também nos sites das secretarias. Porém, percebeu-se que alguns Estados não haviam desenvolvido uma legislação específica para o tema e utilizavam aquela elaborada pelo Conselho Estadual de Educação (CEE). Assim, os sites dos CEEs também foram consultados a fim de identificar as legislações pertinentes e, nestas, as terminologias utilizadas.

Os termos encontrados nas legislações e nas orientações oficiais são apresentados no Quadro 1. Destaca-se que não foram encontradas, nos meios virtuais consultados, as legislações do Estado de São Paulo e do Distrito Federal, bem como as orientações oficiais do Estado da Bahia, relativas ao desenvolvimento das práticas pedagógicas escolares na pandemia.

Cabe ressaltar as diferenças entre as terminologias presentes nas legislações e aquelas utilizadas pelas redes em seus programas e estratégias de desenvolvimento das práticas pedagógicas na pandemia. Algumas redes até citam a legislação estadual como referência, mas optam por utilizar uma terminologia diferente da que consta na lei.

No caso do Rio Grande do Norte (RN), por exemplo, a rede usa as expressões "atividades remotas"; "atividades não presenciais"; e "aprendizagem digital", enquanto a legislação utiliza "modalidade de Educação a Distância". No documento intitulado Nota de Orientação Normativa e de Procedimentos, do Conselho Estadual de Educação do RN, consta que "[...] no Ensino Fundamental, no Ensino Médio e nas Modalidades de Educação Profissional e de Educação de Jovens e Adultos, na atual situação emergencial, quaisquer componentes curriculares poderão 
ser trabalhados na modalidade a distância" (RIO GRANDE DO NORTE, 2020, p. 2). Consta no site da Secretaria Estadual de Educação que: "Pensando em soluções que possam ser utilizadas por todas as redes, a SEEC apresentou a Escola Digital, ambiente virtual de aprendizagem disponível dentro da estrutura do Sistema Integrado de Gestão da Educação" (SEEC, 2020, n. p.). Assim, o uso da expressão "aprendizagem digital" pode estar relacionado à adoção da plataforma Escola Digital e não a um direcionamento legal.

Quadro 1 - Terminologias encontradas nas orientações oficiais e legislações por Unidade da Federação (UF).

\begin{tabular}{|c|c|c|}
\hline UF & Orientações oficiais das SEEs & Legislações Estaduais \\
\hline Acre & $\begin{array}{l}\text { Aprendizado em casa; aprendizagem on- } \\
\text { line }\end{array}$ & Atividades não presenciais \\
\hline Alagoas & $\begin{array}{l}\text { Aulas não presenciais; aprendizagem em } \\
\text { casa; Regime Especial de Atividades } \\
\text { Escolares Não Presenciais (REAENP) }\end{array}$ & $\begin{array}{l}\text { Regime Especial de Atividades Escolares } \\
\text { Não Presenciais (REAENP) }\end{array}$ \\
\hline Amapá & Atividades pedagógicas não presenciais & Aulas e atividades não presenciais \\
\hline Amazonas & Aulas não presenciais; aulas a distância & Regime especial de aulas não presenciais \\
\hline Bahia & - & $\begin{array}{l}\text { Atividades curriculares em regime } \\
\text { especial; atividades curriculares nos } \\
\text { domicílios dos estudantes }\end{array}$ \\
\hline Ceará & $\begin{array}{l}\text { Ensino Remoto; atividades a } \\
\text { distância/domiciliares; aulas não } \\
\text { presenciais }\end{array}$ & $\begin{array}{l}\text { Ensino Remoto; atividades a } \\
\text { distância/domiciliares; } \\
\text { estratégias de ensino e } \\
\text { acompanhamento da aprendizagem de } \\
\text { forma remota; aulas não presenciais }\end{array}$ \\
\hline Espírito Santo & $\begin{array}{l}\text { Atividades Pedagógicas Não Presenciais } \\
\text { (APNPs) }\end{array}$ & $\begin{array}{l}\text { Atividades Pedagógicas Não Presenciais } \\
\text { (APNPS) }\end{array}$ \\
\hline Goiás & $\begin{array}{l}\text { Estudos em casa; aulas on-line; aulas } \\
\text { virtuais }\end{array}$ & Aulas não presenciais \\
\hline Maranhão & Ensino Remoto & $\begin{array}{l}\text { Aulas não presenciais; atividades } \\
\text { pedagógicas não presenciais }\end{array}$ \\
\hline Mato Grosso & $\begin{array}{l}\text { Atividades letivas de modo não } \\
\text { presencial; aulas de forma não presencial }\end{array}$ & Atividades pedagógicas não presenciais \\
\hline $\begin{array}{l}\text { Mato Grosso do } \\
\text { Sul }\end{array}$ & $\begin{array}{l}\text { Atividades remotas vinculantes; aula } \\
\text { remota }\end{array}$ & Atividade pedagógica complementar \\
\hline Minas Gerais & $\begin{array}{l}\text { Regime de estudo não presencial; regime } \\
\text { especial de atividades não presenciais; } \\
\text { atividades não presenciais }\end{array}$ & Atividades pedagógicas não presenciais \\
\hline
\end{tabular}




\begin{tabular}{|c|c|c|}
\hline UF & Orientações oficiais das SEEs & Legislações Estaduais \\
\hline Pará & Práticas pedagógicas remotas & Atividades pedagógicas não presenciais \\
\hline Paraíba & $\begin{array}{l}\text { Regime especial de ensino; Ensino } \\
\text { Remoto; formação remota }\end{array}$ & Regime especial de ensino \\
\hline Paraná & $\begin{array}{l}\text { Ensino Remoto; aulas remotas; Educação } \\
\text { a Distância }\end{array}$ & $\begin{array}{l}\text { Atividades escolares não presenciais; } \\
\text { aulas não presenciais; EaD }\end{array}$ \\
\hline Pernambuco & $\begin{array}{l}\text { Estudos e atividades não presenciais; } \\
\text { educação mediada por tecnologias }\end{array}$ & $\begin{array}{l}\text { Atividades extraescolares mediadas por } \\
\text { tecnologias não presenciais }\end{array}$ \\
\hline Piauí & $\begin{array}{l}\text { Regime especial de aulas não } \\
\text { presenciais; aula remota }\end{array}$ & $\begin{array}{l}\text { Modalidade não presencial; ensino não } \\
\text { presencial }\end{array}$ \\
\hline Rio de Janeiro & Ensino Remoto & $\begin{array}{l}\text { Ensino Remoto; atividades escolares não } \\
\text { presenciais }\end{array}$ \\
\hline $\begin{array}{l}\text { Rio Grande do } \\
\text { Norte }\end{array}$ & $\begin{array}{l}\text { Aprendizagem digital; atividades } \\
\text { remotas; atividades não presenciais }\end{array}$ & Modalidade a distância \\
\hline $\begin{array}{l}\text { Rio Grande do } \\
\text { Sul }\end{array}$ & Aulas remotas & $\begin{array}{l}\text { Atividades domiciliares; atividades } \\
\text { pedagógicas não presenciais }\end{array}$ \\
\hline Rondônia & Aulas remotas & Aulas não presenciais \\
\hline Roraima & Ensino Remoto & $\begin{array}{l}\text { Atividades não presenciais; Ensino } \\
\text { Remoto }\end{array}$ \\
\hline Santa Catarina & $\begin{array}{l}\text { Atividades escolares não presenciais; } \\
\text { atividades não presenciais }\end{array}$ & $\begin{array}{l}\text { Regime especial de atividades escolares } \\
\text { não presenciais; Ensino Remoto }\end{array}$ \\
\hline São Paulo & $\begin{array}{l}\text { Ensino a Distância; educação mediada } \\
\text { por tecnologia; aulas a distância }\end{array}$ & - \\
\hline Sergipe & $\begin{array}{l}\text { Atividades escolares não presenciais; } \\
\text { Ensino Remoto de Emergência }\end{array}$ & $\begin{array}{l}\text { Atividades educacionais } \\
\text { complementares não presenciais; } \\
\text { atividades escolares não presenciais }\end{array}$ \\
\hline Tocantins & $\begin{array}{l}\text { Atividades educacionais não presenciais; } \\
\text { aulas não presenciais }\end{array}$ & Atividades não presenciais \\
\hline Distrito Federal & $\begin{array}{l}\text { Ensino Remoto; Ensino mediado (aulas } \\
\text { mediadas por tecnologia); Ensino on-line; } \\
\text { atividades híbridas, Ensino Remoto, } \\
\text { atividades pedagógicas não presenciais, } \\
\text { atividades não presenciais, tecnologias } \\
\text { remotas }\end{array}$ & - \\
\hline
\end{tabular}

Fonte: Elaborado pelos autores com base na pesquisa realizada (2021). 
A Escola Digital é uma plataforma gratuita de busca que oferece a professores, gestores e redes de ensino os recursos digitais de aprendizagem. Conforme informações disponíveis no próprio site, a plataforma é "uma iniciativa da Fundação Telefônica Vivo e do Instituto Natura, tendo como apoiadores a Fundação Lemann e a Fundação Vanzolini” (ESCOLA DIGITAL, 2021). Percebeu-se, nesse caso, que a escolha da terminologia pode estar mais relacionada à atuação de organizações externas do que a opções pedagógicas. Retoma-se, aqui, Selwyn (2011), no argumento de que a linguagem utilizada no campo da tecnologia educacional não deve ser tratada simplesmente como palavras, termos, frases e declarações benignas ou neutras. Pelo contrário, é um meio poderoso de fazer avançar os interesses e agendas de alguns grupos sociais sobre os interesses de outros.

Tem sido comum no Brasil, nos últimos anos, a participação de instituições não governamentais na rede pública, como já destacado por diversos pesquisadores (ADRIÃO et al., 2009; ADRIÃO; PERONI, 2005; DOURADO, 2007; LEHER, 2003). Adrião et al. (2009) destacam que entre 1994 a 2007, 161 municípios do Estado de São Paulo declararam ter parcerias entre suas redes municipais de educação e instituições privadas. Para as autoras, esse tipo de parceria é uma estratégia adotada pelos governantes a partir de 1990, com a reforma do Estado, tendo como justificativa uma suposta crise de eficácia da administração pública.

Há, ainda, diferentes termos sendo utilizados no mesmo texto da lei e nos textos das orientações oficiais. Na legislação do Estado do Paraná, por exemplo, são utilizados os termos "aulas remotas", "Ensino Remoto" e "Educação a Distância". Nas orientações oficiais da secretaria de educação do Distrito Federal são citados vários termos como "Ensino Remoto", "Ensino mediado", "Ensino on-line", "atividades pedagógicas não presenciais". Na página inicial do programa Escola em Casa DF, consta a seguinte mensagem: "O ensino mediado é a alternativa para os estudantes não perderem o ano letivo, até que as condições impostas pela pandemia permitam a retomada das aulas presenciais". (SEEDF, 2020, n. p.).

Ainda em relação aos dados do Quadro 1, foi identificado que as expressões "educação" e "práticas pedagógicas" são utilizadas poucas vezes (4 e 1 respectivamente), sendo mais utilizadas as terminologias "atividades" (36), "aula" (19) e "ensino" (19).

Na gramática, os adjetivos são palavras que caracterizam um substantivo, conferindo-lhe uma qualidade, característica, aspecto ou estado. Assim, para a denominação das práticas pedagógicas quanto ao seu desenvolvimento na pandemia, foram localizadas 57 adjetivações diferentes nas orientações oficiais e 41 nas legislações, conforme indicado na Tabela 1.

Inicialmente, destaca-se o fato de que dez adjetivações diferentes foram utilizadas nos estados e no Distrito Federal, corroborando a hipótese inicial quanto à profusão terminológica para identificar as práticas pedagógicas realizadas durante a pandemia.

A adjetivação citada com mais frequência foi aquela relacionada a não presencialidade, tendo sido mencionada 50 vezes nos textos analisados. A segunda expressão mais recorrente foi a "remota/o" (23).

Importante ressaltar que as terminologias "não presencial" e "remota" não possuíam representatividade na área até o estabelecimento da pandemia. No campo acadêmico, uma obra recente, intitulada Dicionário Crítico de Educação e Tecnologias e de Educação a Distância, foi publicada em 2018, sob a organização do professor e pesquisador Daniel Mill, reunindo 
importantes pesquisadores brasileiros da área da educação e comunicação. Logo nas páginas iniciais, Mill (2018) afirma que a publicação "é fruto de um intenso esforço coletivo, para reunir diversos pesquisadores interessados em, juntos, pensar a relação entre a educação e as tecnologias". (MILL, 2018, p. 5). Nessa publicação, não constam os verbetes "educação remota", "Ensino Remoto", "Ensino não presencial” ou "educação não presencial”, apesar de esses serem os mais utilizados nos documentos estaduais analisados.

Tabela 1 - Terminologias encontradas para a denominação das práticas pedagógicas na pandemia.

\begin{tabular}{|c|c|c|c|}
\hline Terminologias & $\begin{array}{l}\text { Nas orientações } \\
\text { oficiais das SEEs }\end{array}$ & $\begin{array}{c}\text { Nas legislações } \\
\text { Estaduais }\end{array}$ & Total \\
\hline Não presenciais & 24 & 26 & 50 \\
\hline Remotas & 18 & 5 & 23 \\
\hline Em casa/Domiciliares & 4 & 3 & 7 \\
\hline A distância & 3 & 3 & 6 \\
\hline $\begin{array}{l}\text { Mediadas por } \\
\text { tecnologia }\end{array}$ & 3 & 1 & 4 \\
\hline Especiais & 1 & 2 & 3 \\
\hline On-line & 2 & - & 2 \\
\hline Híbridas & 1 & - & 1 \\
\hline Digitais & 1 & - & 1 \\
\hline Complementares & - & 1 & 1 \\
\hline TOTAL & 57 & 41 & \\
\hline
\end{tabular}

Fonte: Elaborada pelos autores com base na pesquisa realizada (2021).

Com relação ao termo "não presencial", destaca-se que no campo da educação e tecnologias e da Educação a Distância, este não costuma ser utilizado para conceituar nenhuma prática, já que é uma expressão abrangente.

Legalmente, no Brasil, a alternativa à modalidade presencial é a modalidade de Educação a Distância (EaD), tanto para a educação superior quanto, em casos emergenciais, para a Educação Básica, com as suas possibilidades de efetivação, mas também com suas obrigações legais.

Contudo, para atender à situação inédita criada pela pandemia, o Conselho Nacional de Educação buscou definir as atividades não presenciais quando, no Parecer CNE/CP N. 5/2020, cita que tais atividades são entendidas como "aquelas a serem realizadas pela instituição de ensino com os estudantes quando não for possível a presença física destes no ambiente escolar". (BRASIL, 2020b, p. 6).

Quanto à expressão "remoto/a", encontra-se no dicionário comum a sua etimologia, sendo indicada como derivada do latim remotus, que significa afastado, longe, removido. Já o verbete 
remoto pode significar: "Que aconteceu há muito tempo, antigo"; "Longe no tempo ou no espaço, distanciado"; "Pouco provável"; "Que se efetiva à distância" (DICIO, 2020). O mesmo dicionário indica que, na área da informática, remoto significa algo "cuja realização se dá através da conexão entre computadores e mecanismos semelhantes, ainda que estes estejam longe uns dos outros: conexão remota”. (DICIO, 2020).

A expressão "remoto/a", até então, era usualmente utilizada nas áreas da informática, da computação e da tecnologia da informação, mas não na área da educação.

Ao analisar os possíveis significados apresentados no dicionário para o termo remoto, vêse que tais acepções se relacionam a ações realizadas à distância ou com distanciamento temporal ou espacial, semelhante ao que acontece nos conceitos de EaD presentes na legislação brasileira.

No Brasil, desde 1998, há um conceito legal para a Educação a Distância, o qual contempla vários aspectos. $O$ Decreto $n^{\circ} 2.494 / 1998$, Art. $1^{\circ}$ indica a EaD como:

[...] uma forma de ensino que possibilita a autoaprendizagem, com a mediação de recursos didáticos sistematicamente organizados, apresentados em diferentes suportes de informação, utilizados isoladamente ou combinados, e veiculados pelos diversos meios de comunicação (BRASIL, 1998).

Percebe-se que, nesse momento, a caracterização da EaD era bastante baseada nos suportes tecnológicos e não havia referência à presencialidade ou a não presencialidade, ou à separação espaço-temporal entre os sujeitos do processo de ensino e aprendizagem, tal como ocorre no Decreto n ${ }^{0}$ 5.622/2005 (BRASIL, 2005, p. 1):

A Educação a Distância é uma modalidade educacional na qual a mediação didático-pedagógica nos processos de ensino e aprendizagem ocorre com a utilização de meios e tecnologias de informação e comunicação, com estudantes e professores desenvolvendo atividades educativas em lugares ou tempos diversos.

O Decreto $n^{\circ} 9.057 / 2017$ (que revoga o $n^{\circ} 5.622 / 2005$ ) também permanece destacando a separação temporal e espacial como uma das principais características da EaD. No Art. $1^{\circ}$ consta que:

[...] considera-se Educação a Distância a modalidade educacional na qual a mediação didático-pedagógica nos processos de ensino e aprendizagem ocorra com a utilização de meios e tecnologias de informação e comunicação, com pessoal qualificado, com políticas de acesso, com acompanhamento e avaliação compatíveis, entre outros, e desenvolva atividades educativas por estudantes e profissionais da educação que estejam em lugares e tempos diversos (BRASIL, 2017).

Ao analisar tais conceitos pode-se perceber que o foco não é a "não presencialidade", mas sim a realização de atividades educativas em lugares e tempos diversos, além da incorporação de outros elementos imprescindíveis para a EaD, como mediação didático-pedagógica; tecnologias de informação e comunicação; acompanhamento e avaliação; o que representa um avanço conceitual. Dessa maneira, reconhecer determinada prática como EaD requer assumir essas 
condições e não apenas considerar que se trata de uma ação pedagógica desenvolvida por estudantes e professores localizados em lugares e tempos diversos.

Assim, na pandemia as expressões "ensino/educação não presencial" ou "remoto/a" significam simplesmente o oposto de educação/ensino presencial na Educação Básica, sendo aquele caracterizado pela separação física entre os sujeitos do processo de ensino e aprendizagem, sem maiores especificidades.

Identificou-se que o adjetivo "a distância" foi citado apenas seis vezes, em cinco Estados diferentes - Amazonas, Ceará, Paraná, Rio Grande do Norte e São Paulo.

Ressalta-se também que os legisladores brasileiros, apesar de terem previsto a possibilidade de oferta da EaD na Educação Básica em casos emergenciais, dedicaram-se, em especial nos últimos anos, a desenvolver normas para a EaD voltadas ao Ensino Superior. Tal fato pode ser mais um dos motivos que afastou as redes de ensino da escolha pela terminologia "EaD" para caracterizar as práticas pedagógicas na pandemia.

Acredita-se, ainda, que a quase ausência da terminologia "EaD" na pandemia pode estar vinculada ao histórico de preconceito sobre a modalidade no Brasil. Esse preconceito pode estar atrelado à associação da EaD com a educação massificada, sem qualidade, de formação aligeirada, entre outros. Isso denota que a EaD costuma ser olhada de forma simplista e, dessa maneira, vista como um ensino de terceira categoria ou facilitário. Esse modo de pensar está ligado ao forte processo de mercantilização do Ensino Superior no Brasil. Historicamente, as políticas públicas priorizaram a expansão da Educação Superior por meio da privatização, sendo que mais de $80 \%$ desse nível de ensino está sob a responsabilidade da iniciativa privada e, tradicionalmente, as empresas educacionais têm utilizado a EaD para aumentar seus lucros, ofertando cursos aligeirados e de baixa qualidade (CERNY, 2009). Para Cerny (2009), a falta de compreensão do que seja a Educação a Distância contribui para criar resistências também nas comunidades das universidades e escolas de educação básica.

Ademais, a forma de desenvolvimento da EaD no Brasil forjou uma visão de que a modalidade possui um único modelo organizacional e pedagógico, uma única forma de ser realizada. Pode-se citar como exemplo os ambientes virtuais de aprendizagem, que geralmente são voltados a alunos mais velhos, como jovens e adultos. Também costuma ser comum a ideia de que a formação em EaD precisa contar com tutoria e polos de apoio presencial, elementos presentes no modelo de EaD da Universidade Aberta do Brasil (UAB) e também na maior parte das instituições brasileiras de Ensino Superior privadas. Assim, comumente reduz-se a Educação a Distância a uma metodologia; porém, vários modelos ou metodologias são possíveis dentro da EaD, desde que respeitadas as legislações, bem como as necessidades de aprendizagem do público-alvo.

Essa análise não significa ser favorável à adoção da EaD na Educação Básica, muito pelo contrário, pois é indiscutível a importância do contexto escolar presencial na formação das crianças e jovens. Essa reflexão problematiza o fato de que as redes de ensino, ao não adotarem a modalidade a distância, desconsideram as experiências, o histórico e as pesquisas que poderiam iluminar as práticas em tempos de distanciamento físico. Além disso, o novo sem referências faz recair individualmente no professor a responsabilidade por todo o processo de ensino e aprendizagem, e desresponsabiliza os gestores em relação ao investimento necessário 
para a modalidade a distância, como infraestrutura e profissionais de apoio e formação necessários aos processos educacionais com gestão de tecnologias, mesmo que não sejam nominados como EaD.

Quanto aos adjetivos mencionados, verificou-se ainda que aqueles relacionados aos meios digitais ou com as tecnologias de forma geral - "Mediadas por tecnologia", "On-line", "Digital" também foram pouco utilizados, sendo apenas sete referências. Essa situação leva a algumas reflexões quanto à integração das tecnologias na educação.

As tecnologias se fazem presentes na educação escolar desde que ela existe. As visões mais elementares do conceito de tecnologia ou até mesmo o seu "sentido (pré-) histórico", como nos lembra Selwyn (2011, p. 14), indicam que a tecnologia pode ser "compreendida como o processo pelo qual o humano modifica a natureza para satisfazer suas necessidades e anseios" e que ela "se refere ao uso, por humanos, de ferramentas e técnicas para adaptar e controlar o seu meio ambiente". (SELWYN, 2011, p. 14). No entanto, o contexto atual, marcado pela onipresença da tecnologia digital em nosso dia a dia, inclusive no das instituições educativas, pode levar, por vezes, a considerar como tecnologia apenas os recursos disponíveis no formato digital. Para o Instituto Federal de Santa Catarina (IFSC), por exemplo, o Ensino Remoto "nem sempre é mediado por tecnologias e pode se basear, por exemplo, no oferecimento de material impresso para estudo em casa e realização de tarefas" (IFSC, 2020, n. p.). Podemos perceber nessa situação que o material impresso não é considerado uma tecnologia, talvez por não ser digital, que é o padrão emergente das tecnologias de informação e comunicação.

Nesse sentido, torna-se significativo distinguir o que é analógico e o que é digital. Selwyn (2011) nos auxilia nessa tarefa ao afirmar que "'analógico' refere-se a dados que podem ser medidos como um valor que varia continuamente", enquanto o digital "refere-se, simplesmente, a dados descontínuos, baseados em dois estados distintos - 'ligado' ou 'desligado' (ou 1 e 0 )". 0 autor denomina, ainda, de "pré-digitais" as tecnologias como o livro texto ou a caneta. (SELWYN, 2011, p. 30). Por meio dessas definições, percebe-se que os recursos analógicos também são tecnologias e não apenas os digitais. $O$ autor complementa, ainda, ao afirmar que: "A distinção entre digital e analógico pode parecer um detalhe técnico sutil, mas é crucial para a explicação de porque as tecnologias digitais desempenham um papel tão importante na sociedade contemporânea" (SELWYN, 2011, p. 25).

Para Selwyn (2011), as vantagens técnicas das tecnologias digitais fundamentaram a ideia de que elas estão associadas a um número de qualidades e características mais abrangentes. 0 autor destaca que há, inclusive, uma percepção geral de que as tecnologias digitais são mais precisas, exatas e eficientes do que as máquinas e métodos analógicos. "Tecnologias digitais são vistas como base para o desenvolvimento de processos e atividades em escalas muito maiores do que antes, e de formas mais rápidas e poderosas" (SELWYN, 2011, p. 27). Espíndola, Cerny e Xavier (2020) discutem que a percepção dos professores sobre tecnologia está relacionada a valores de eficácia e progresso, geralmente associados aos novos artefatos tecnológicos ainda não transparentes no processo pedagógico.

Dessa forma, destaca-se que não há Educação a Distância, Ensino Remoto ou Educação não presencial sem o uso de tecnologias, sejam elas analógicas ou digitais. Mesmo no caso das escolas que tenham realizado práticas pedagógicas por meio da entrega de livros didáticos 
presencialmente, seguida do recebimento presencial das atividades realizadas, está presente o uso de tecnologias, já que o livro impresso é uma tecnologia.

Assim, ainda que imprescindível, o uso da tecnologia não foi o foco quando da caracterização das práticas pedagógicas na pandemia, possivelmente pelo entendimento errôneo quanto ao que possa ser considerado como tecnologia, e também, corroborando com as afirmações de Selwyn (2011, p. 1), pelo fato de que a "tecnologia em contextos educacionais parece ter se tornado tão corriqueira, que, para muitos, entrou no universo do 'senso comum'”.

\section{CONCLUSÃO}

Com o intuito de identificar como têm sido caracterizadas as práticas pedagógicas das redes estaduais na pandemia e refletir sobre as implicações dessas caracterizações para o campo da tecnologia educacional, foi realizado um estudo documental e exploratório, acerca das terminologias utilizadas pelas secretarias estaduais e distrital de educação brasileiras e citadas nas legislações estaduais e distrital.

Nesse sentido, identificou-se que a caracterização realizada foi marcada pela profusão terminológica, com destaque para a presença de terminologias novas, portanto, ausentes de definições conceituais ou legais até a pandemia, como "Ensino Remoto", "atividades pedagógicas não presenciais" e tantas outras.

A criação de novos termos, sem a preocupação de conceituá-los, permite inferir que o novo pode abarcar qualquer coisa, inclusive a responsabilização individual do professor pelo desenvolvimento de todo o processo de ensino e aprendizagem, como a gestão das tecnologias.

Nessa lacuna das políticas públicas, está se abrindo um espaço enorme para as corporações entrarem na educação pública para a comercialização de tecnologias, com todas as implicações que isso significa: desde a perda de autonomia de professores e gestores locais na escolha e criação de materiais e currículo, até a perda da soberania pela captura dos dados de estudantes e professores. Dantas (SANTOS, 2020, n. p.) considera "uma tragédia a longo prazo, porque se está entregando a essas plataformas a própria formação da identidade e da cultura brasileira".

O termo "Educação a Distância", apesar de constar na LDB como a modalidade alternativa à Educação presencial em casos de emergência sanitária, entre outros, foi pouco utilizado, como apontado na hipótese de pesquisa. O esquivamento em relação à expressão Educação a Distância nas legislações e na gestão da Educação Básica parece estar mais relacionado a questões políticas do que pedagógicas, evidenciando um desconhecimento sobre a modalidade EaD, associada a um único modelo pedagógico ou reduzida a uma metodologia de ensino.

A quase ausência da expressão Educação a Distância parece indicar que, mesmo havendo estudos apontando que a EaD pode oferecer a mesma qualidade da Educação presencial, ainda há preconceito quanto à modalidade, já que no Brasil é comum a EaD estar vinculada a interesses mercantilistas e privatistas.

Ainda, parecem estar presentes a preocupação com o não cumprimento das normas legais previstas para a EaD no Brasil, bem como com o investimento necessário para a modalidade. Também parecem estar presentes a preocupação com o não cumprimento das normas legais 
previstas para a EaD no Brasil, bem como com o investimento necessário para a modalidade. Considerando, ainda, que a legislação da EaD não costuma ser suficiente para normatizar toda a especificidade do trabalho dos profissionais que atuam nessa modalidade, inclusive os professores, o uso de novas terminologias no Ensino Remoto se isenta de uma regulamentação específica, engendrando um novo trabalhador docente, que desenvolve suas atividades em condições precárias, como: elevada carga horária, número excessivo de alunos, remuneração incompatível com a carga horária, despesas com os equipamentos tecnológicos necessários, gestão das tecnologias, entre outros. Esse cenário traz o alerta para a necessidade urgente de pesquisas que possam identificar e sistematizar essa perversa realidade trabalhista imposta aos docentes pelo trabalho remoto.

Neste estudo, notou-se que a profusão de expressões no campo didático-pedagógico aliouse à profusão terminológica no campo da tecnologia educacional, quando as práticas escolares desenvolvidas na pandemia precisaram ser caracterizadas pelas redes estaduais de alguma forma.

Ademais, foram identificadas, nos sites das secretarias, várias referências ao Ensino Híbrido, já que algumas redes, no final do ano de 2020, realizavam determinadas atividades presenciais. Em 2021, é provável que as redes se reorganizem novamente tendo em vista o atendimento de uma nova realidade que mescla atividades presenciais com as não presenciais.

Igualmente, nos sites das secretarias, foram observadas inúmeras informações quanto à formação dos professores para a atuação emergencial na educação não presencial e, possivelmente, na híbrida, muitas vezes com parcerias externas às redes.

Caberá aos pesquisadores da área dar continuidade aos estudos, visando à compreensão desses novos fenômenos que se desenvolvem na educação escolar, no Brasil e em quase todas as partes do mundo.

\section{REFERÊNCIAS}

ADRIÃO, T. et al. Uma modalidade peculiar de privatização da educação pública: a aquisição de "sistemas de ensino" por municípios paulistas. Educação e Sociedade, Campinas, v. 30, n. 108, p. 799-818, out. 2009. Disponível em: http://www.scielo.br/scielo.php?script=sci_arttext\&pid=S010173302009000300009\&lng=en\&nrm=iso. Acesso em: 20 jan. 2021.

ADRIÃO, T.; PERONI, V. (Org.). O público e o privado na educação: interfaces entre Estado e sociedade. São Paulo: Xamã, 2005.

BRASIL. Decreto $n^{\circ} 2.494$, de 10 de fevereiro de 1998. Regulamenta o art. 80 da Lei $n^{\circ} 9.394$, de 20 de dezembro de 1996, e dá outras providências. Diário Oficial da União: seção 1, Brasília, DF, p. 1, 11 fev. 1998. Disponível em: https://www2.camara.leg.br/legin/fed/decret/1998/decreto-2494-10-fevereiro-1998397980-publicacaooriginal-1-pe.html. Acesso em: 24 mai. 2021.

BRASIL. Decreto presidencial $n^{\circ}$ 5622/2005. Regulamenta o art. 80 da Lei no 9.394, de 20 de dezembro de 1996 , que estabelece as diretrizes e bases da educação nacional. Diário Oficial da União: seção 1, Brasília, DF, p. 1, 20 dez. 2005. Disponível em: http://www.planalto.gov.br/ccivil_03/_ato20042006/2005/decreto/d5622.htm\#\%20. Acesso em: 25 jul. 2020. 
BRASIL. Decreto presidencial n. 9.057/2017. Regulamenta o Art. 80 da Lei $n^{\circ} 9.394$, de 20 de dezembro de 1996. Diário Oficial da União: seção 1, Brasília, DF, edição 100, p. 3, 26 mai. 2017. Disponível em: https://www.in.gov.br/materia/-/asset_publisher/Kujrw0TZC2Mb/content/id/20238603/do1-2017-05-26decreto-n-9-057-de-25-de-maio-de-2017-20238503. Acesso em: 28 jul. 2020.

BRASIL. Lei n 9.394, de 20 de dezembro de 1996. Lei das Diretrizes e Bases da Educação Nacional. Estabelece as diretrizes e bases da educação nacional. Diário Oficial da União: seção 1, Brasília, DF, p. 27933, 23 dez. 1996. Disponível em: http://www.planalto.gov.br/ccivil_03/LEIS/19394.htm. Acesso em: 17 jul. 2020.

BRASIL. Medida provisória ${ }^{\circ} 934$ de $1^{\circ}$ de abril de 2020. Estabelece normas excepcionais sobre o ano letivo da educação básica e do ensino superior decorrentes das medidas para enfrentamento da situação de emergência de saúde pública. Diário Oficial da União: seção 1: extra, Brasília, DF, edição 63-A, p. 1, 1 abr. 2020a. Disponível em: http://www.in.gov.br/en/web/dou/-/medida-provisoria-n-934-de-1-de-abrilde-2020-250710591. Acesso em: 17 jul. 2020.

BRASIL. Ministério da Educação. Conselho Nacional de Educação. Parecer n 05, de 28 de abril de 2020. Dispõe sobre a reorganização do Calendário Escolar e da possibilidade de cômputo de atividades não presenciais para fins de cumprimento da carga horária mínima anual, em razão da Pandemia da COVID19. Diário Oficial da União: seção 1, Brasília, DF, n. 83, p. 63, 04 mai. 2020b. Disponível em: http://portal.mec.gov.br/index.php?option=com_docman\&view=download\&alias=145011-pcp00520\&category_slug=marco-2020-pdf\&ltemid=30192. Acesso em: 11 jan. 2021.

BRASIL. Ministério da Educação. Conselho Nacional de Educação. Resolução CNE/CEB n 3 de 21 de novembro de 2018. Atualiza as Diretrizes Curriculares Nacionais para o Ensino Médio. Diário Oficial da União: seção 1, Brasília, DF, 21 nov. 2020. Disponível em:

http://portal.mec.gov.br/index.php?option=com_docman\&view=download\&alias=102481-rceb00318\&category_slug=novembro-2018-pdf\&Itemid=30192. Acesso em: 11 jan. 2021.

CERNY, R. Z. Gestão pedagógica na educação a distância: análise de uma experiência na perspectiva da gestora. 2009. Tese (Doutorado em Educação) - Pontifícia Universidade Católica de São Paulo, São Paulo, 2009. Disponível em: https://leto.pucsp.br/bitstream/handle/10115/1/Roseli\%20Zen\%20Cerny.pdf. Acesso em: 11 jan. 2021.

DICIO. Remoto. 2020. Disponível em: https://www.dicio.com.br/remoto/. Acesso em: 11 jan. 2021.

DOURADO, L. F. Políticas e gestão da educação básica no Brasil: limites e perspectivas. Educação e Sociedade, Campinas, v. 28, n. 100, p. 921-946, out. 2007. Disponível em: https://www.scielo.br/j/es/a/w6QjW7pMDpzLrfRD5ZRkMWr/abstract/?lang=pt. Acesso em: 20 jan. 2021.

ESCOLA DIGITAL. 0 que é a Escola Digital? 2021. Disponível em: https://escoladigital.org.br/pagina/sobre-nos. Acesso em: 19 jan. 2021.

ESPÍNDOLA, M. B.; CERNY, R. Z.; XAVIER, R. S. As perspectivas de tecnologia dos educadores em formação: valores em disputa. Reveduc: Revista Eletrônica de Educação, São Carlos, v. 14, p. 1-17, jan./dez. 2020. Disponível em: http://www.reveduc.ufscar.br/index.php/reveduc/article/view/3833. Acesso em 24 mai 2021.

FEENBERG, A. Tecnologia, Modernidade e Democracia. Lisboa: Inovatec, 2018.

FOSTER, J. B. Educação e a crise estrutural do capital: o caso dos Estados Unidos. Perspectiva, Florianópolis, v. 31, n. 1, p. 85-136, jan./abr. 2013. Disponível em: http://dx.doi.org/10.5007/2175795X.2013v31n1p85. Acesso em: 20 jan. 2021. 
FREITAS, L. C. Os reformadores empresariais da educação e a disputa pelo controle do processo pedagógico na escola. Educação e Sociedade, Campinas, v. 35, n. 129, p. 1085-1114, out./dez. 2014. Disponivel em: https://www.scielo.br/j/es/a/xm7bSyCfyKm64zWGNbdy4Gx/abstract/?lang=pt. Acesso em: 20 jan. 2021.

GHEDIN, E.; FRANCO, M. A. S. Questões de método na construção da pesquisa em educação. São Paulo: Cortez, 2008.

HABOWSKI, A. C. Tecnologias e educação: conhecer o outro lado. Curitiba: Appris, 2020.

INSTITUTO FEDERAL DE SANTA CATARINA (IFSC). Atividades não presenciais $\mathbf{X}$ Educação a distância: é tudo a mesma coisa? 2020. Disponível em: http://palhoca.ifsc.edu.br/index.php/1040-atividades-naopresenciais-x-educacao-a-distancia-e-tudo-a-mesma-coisa. Acesso em: 13 jan. 2021.

IWASSO, S. Nota mais alta não é educação melhor. 2010. Disponível em: http://www.estadao.com.br/noticias/impresso, notamais- -alta-nao-e-educacao-melhor,589143,0.htm. Acesso em: 20 jan. 2021.

LEHER, R. Reforma do Estado: o privado contra o público. Trabalho, Educação e Saúde, Rio de Janeiro, v. 1, n. 2, p. 203-228, set. 2003. Disponível em: https://www.scielo.br/j/tes/a/NhjhPwHSQNc99GT6kjdCNDC/abstract/?lang=pt. Acesso em: 20 jan. 2021.

MILL, D. (Org.). Dicionário crítico de educação e tecnologias e de educação a distância. Campinas: Papirus, 2018.

OLIVEIRA, P. B. R. A concepção bakhtiniana da linguagem: a ideologia presente nos enunciados que configuram a comunicação verbal. Revista Thêma et Scientia, Cascavel, v. 1, n. 1, jan./jun. 2011. Disponível em: https://www.fag.edu.br/upload/arquivo/1322653351.pdf. Acesso em: 22 dez. 2020.

RIO GRANDE DO NORTE. Conselho Estadual de Educação. Nota de Orientação Normativa e de Procedimentos. Natal, 19 mar. 2020. Disponível em:

https://sesieducacao.com.br/conteudos/legislacao/2625a991bf42c19e9560249b97d3cea5.pdf. Acesso em: 9 jan. 2021.

SANTOS, J. V. A privatização da educação através das plataformas de ensino remoto: entrevista especial com Marcos Dantas. 2020. Disponível em: http://www.ihu.unisinos.br/159noticias/entrevistas/603420-a-privatizacao-da-educacao-atraves-das-plataformas-de-ensino-remotoentrevista-especial-com-marcos-dantas. Acesso em: 9 jan. 2021.

SECRETARIA DO ESTADO DA EDUCAÇÃO, DA CULTURA, DO ESPORTE E DO LAZER DO RIO GRANDE DO NORTE (SEEC). Educação do RN ampliará o uso de ferramentas digitais no ensino. 2020. Disponível em: http://www.educacao.rn.gov.br/Conteudo.asp?TRAN=ITEM\&TARG=227382\&ACT=\&PAGE=0\&PARM=\&LBL= ACERVO+DE+MAT\%C9RIAS. Acesso em: 19 dez. 2020.

SECRETARIA DE ESTADO DA EDUCAÇÃO DO DISTRITO FEDERAL (SEEDF). Escola Em Casa DF: Início. 2020. Disponível em: http://www.educacao.df.gov.br/escola-em-casa/. Acesso em: 19 dez. 2020.

SELWYN, N. Minding our language: why education and technology is full of bullshit... and what might be done about it. Learning, Media and Technology, v. 41, n. 3, p. 437-443, 2016. Disponível em: http://dx.doi.org/10.1080/17439884.2015.1012523. Acesso em: 25 nov. 2020.

SELWYN, N. O que queremos dizer com "educação" e "tecnologia"? In: SELWYN, N. Education and Tecnology: key issues and debates. Londres: Bloomsbury, 2011. Disponível em: 
https://ticpe.files.wordpress.com/2016/12/neil_selwyn_keyquestions_cap1_trad_pt_final1.pdf. Acesso em: 28 nov. 2020.

SHIROMA, E. O. et al. A Tragédia Docente e suas Faces. In: EVANGELISTA, O.; SEKI, A. K. (Orgs.). Formação de professores no Brasil: leituras a contrapelo. Araraquara: Junqueira \& Marin, 2017.

UNIÃO NACIONAL DOS DIRIGENTES MUNICIPAIS DE EDUCAÇÃO (UNDIME). Pesquisa revela que $96 \%$ das redes municipais de educação estão realizando atividades não presenciais com os alunos durante a pandemia. 2020. Disponível em: https://undime.org.br/noticia/10-09-2020-09-48-pesquisa-revela-que-96das-redes-municipais-de-educacao-estao-realizando-atividades-nao-presenciais-com-os-alunos-durantea-pandemia. Acesso em: 22 dez. 2020.

WENGER, E. Uma teoria social da aprendizagem. In: ILLERIS, K. (Org.). Teorias contemporâneas da aprendizagem. Porto Alegre: Artmed, 2013. 